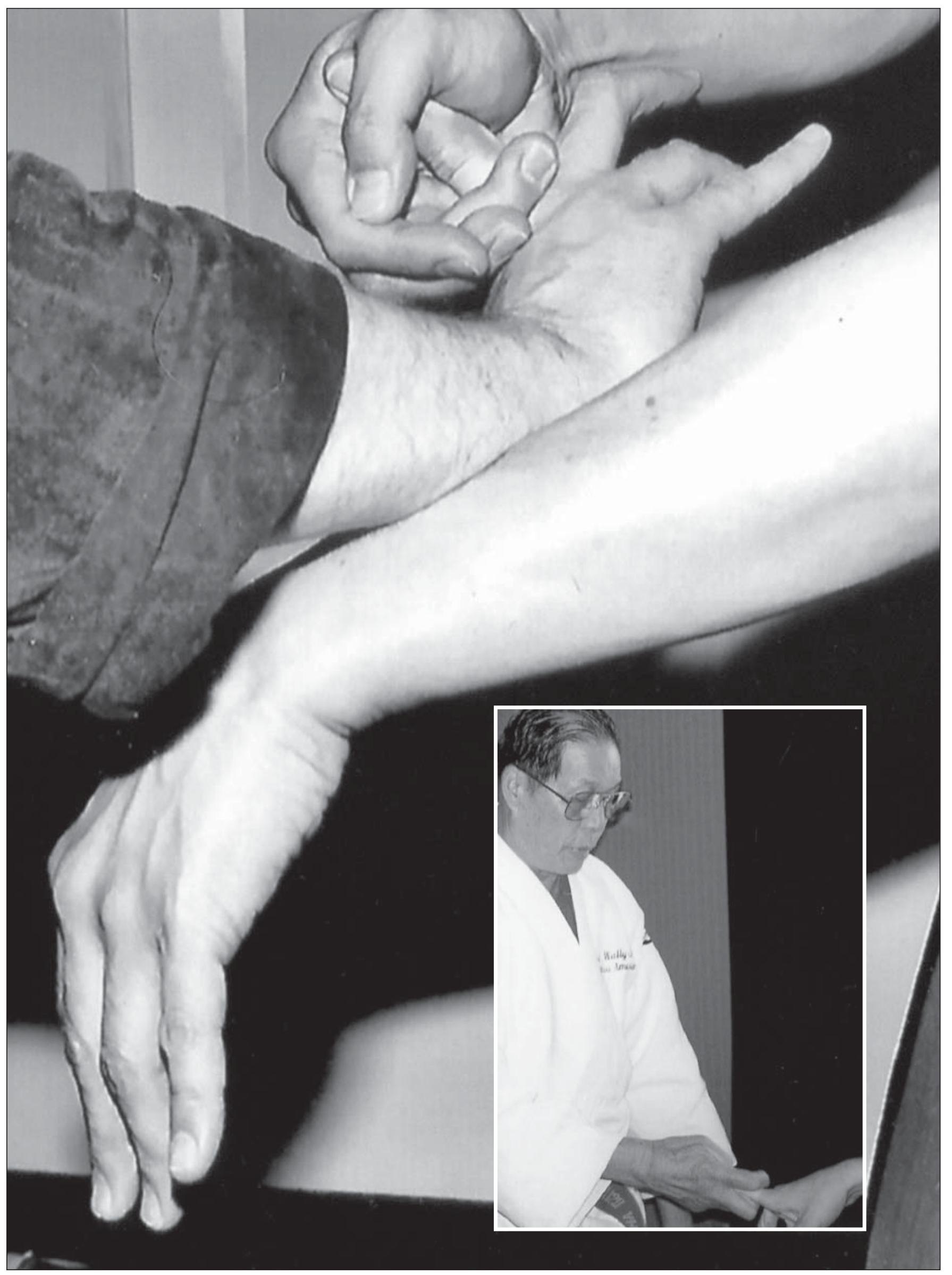




\title{
Enseñando agradablemente: Wally Jay compartiendo los principios marciales
}

\author{
Entrevista por Peter Hobart
}

\section{Introducción}

Cualquiera que haya entrenado con Wally Jay, fundador del Jujitsu del Pequeño Círculo, estará de acuerdo con que este caballero es la encarnación viviente de los más altos ideales de las artes marciales. Reconocido en todo el mundo por su gran habilidad en el combate, templa su potente aplicación de la técnica con un comportamiento humilde, un contagioso sentido del humor y un noble espíritu.

A lo largo de los pasados cincuenta años, Wally Jay ha sido honrado con innumerables distinciones por parte de organizaciones tanto de dentro como de fuera de la comunidad marcial. Además de sus logros personales como pionero e innovador de las artes marciales, también ha entrenado a muchos otros hacia la victoria en diversos contextos competitivos, acentuando su generosa voluntad de compartir sus facultades con los demás, una de las cualidades por la que es mejor conocido.

Desde agosto de 2002, el "Profesor" (como le llaman sus estudiantes) ha adoptado un papel de algún modo menos activo en los asuntos de la enseñanza diaria, trasladándola a las tres personas que ha designado para llevar los principios de sus sistema a las generaciones futuras, especialmente a su hijo Leon Jay. Al conversar con el "Profesor" Jay, sin embargo, es evidente que su arte, sus ideales y su familia marcial permanecen en un lugar muy alto en sus pensamientos. El domingo 14 de marzo de 2004 entrevisté al "Profesor" Jay sobre estas y otras cuestiones.

\section{Sobre sus primeras influencias y experiencias en las artes marciales:}

Comencé en las artes marciales cuando tenía dieciocho años, pero ya boxeaba cuando tenía doce... El boxeo me ayudó mucho: cómo calibrar las distancias, a mantenerme siempre sobre la bola del pie [eminencia metatarsiana]. En judo deslizas los pies, no subes alto las piernas. Permaneces cerca del suelo con el peso sobre la bola del pie. Permaneces cerca del suelo y eso te ayuda a lograr más fácilmente la posición.

(página previa)

El profesor Wally Jay y un primer plano de un bloqueo a un dedo de la mano, demostrado por su hijo Leon Jay. 
Paul Kaelemakule fue mi primer entrenador, pero no duramos mucho cayendo sobre un duro suelo de madera. Mi primer profesor de artes marciales fue Juan Gómez, en 1940. Él me enseñó Okazaki Kodenkan Jujutsu. El profesor Okazaki me enseñó las artes profundas, cómo lisiar a una persona, cómo lesionarla gravemente... El profesor Okazaki fue la primera persona que enseñó jujutsu a los no japoneses, y a la comunidad japonesa no le gustó aquello y le discriminaron, pero después de un tiempo tuvo muchos amigos, amigos caucásicos y de diferentes nacionalidades, y también amigos japoneses. Era un rebelde porque se esperaba que no enseñase más que a japoneses.

\section{Sobre su ruptura con la tradición:}

El sistema del profesor Okazaki, el Kodenkan -que yo estaba enseñando-, lo traté de cambiar después de obtener mi cinturón negro. Traté de improvisar cosas diferentes para hacerlo mejor. El grupo Okazaki quería que enseñase exactamente del modo en que enseñaba el profesor Okazaki. Yo les dije "no puedes luchar en la Segunda Guerra Mundial con armas de la Primera Guerra Mundial". Pero, por tradición, se espera que no cambies, por lo que fui considerado un rebelde. Ellos me rechazaron después de aquello, pero años después volvimos a ser amigos.

El autor vivencia una serie de bloqueos de brazo y pierna.

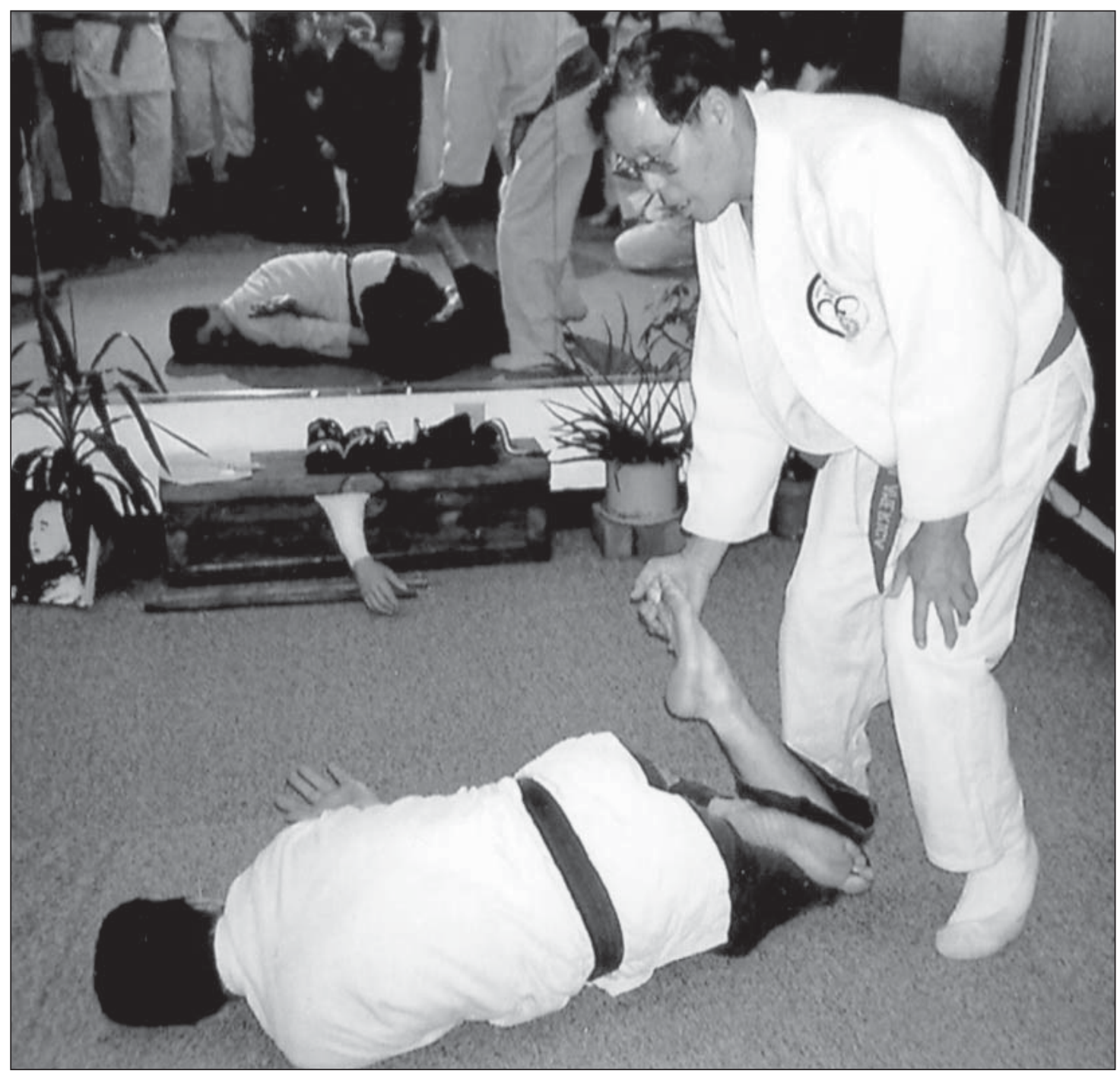


Encontré a un tipo llamado Ken Kawachi que era profesor de judo. Era $3^{\text {er }}$ Dan. Se unió al grupo del Profesor Okazaki y en tres meses obtuvo su cinturón negro. Hice amistad con él y me dijo que fuese a su clase. Lo hice y descubrí muchas cosas: las acciones en dos direcciones, desplazarse deslizando los pies en vez de caminar (esto también lo aprendí del boxeo). Todas las escuelas de jujutsu estaban enseñando en aquel momento que se caminaba, pero si deslizas los pies lo consigues más deprisa, logras la posición más rápidamente. Así, cuando el profesor Okazaki hizo su primer torneo, en Hawai, invitó a todo el mundo -su gente, la gente del Kodenkan, la gente del Kodokan...- Los otros ganaron todo. Lo único que ganamos fue aquello en lo que los demás no llevaban ningún competidor. El profesor Okazaki estaba avergonzado y dijo que iba a contratar un instructor japonés, pero murió en 1951 antes de que esto sucediese.

Entrené con Ken Kawachi desde 1942 a 1944. Estaba en mi clase -la clase del sensei Gómez-, y el sensei Gómez iba a promocionarme a cinturón amarillo, pero no lo acepté. No pensé que lo mereciera. No quería cogerlo, pero no quería discutir con el sensei Juan Gómez. Ken Kawachi preguntó: ¿Por qué no lo coges?" Cedí y lo cogí, pero después de aquello le dije: "Voy a dejarlo". Kawachi me preguntó el porqué y le dije: “iNi siquiera puedo hacer las tijeras voladoras!”. No podía proyectar al compañero, y me caía porque no hacía bien la técnica [técnica de las tijeras]. Entonces dijo: "Ven a mi clase". Cuando fui a su clase de jujutsu aprendí muchas cosas sobre la muñeca. Ten en cuenta que él sólo pesaba 135 libras [61kg.] y era campeón Open de Hawai. Me enseñó cómo usar las muñecas. Podía lanzar personas por encima de mi, ¡era muy fuerte! Te sorprendería...

No tengo la misma constitución que Kawachi. Kawachi tenía una constitución fuerte. Medía como 1,60 m. y pesaba $61 \mathrm{~kg}$. Tenía una postura muy fuerte y todo lo demás. Yo medía 1,75 m. y pesaba como $56,7 \mathrm{~kg}$. ... El profesor Okazaki me dio los fundamentos. Creo que el más grande fue Kawachi, me enseñó cosas que nadie me había mostrado nunca antes. Era un campeón, pero se unió a la clase del profesor Okazaki y aprendió todas las técnicas y llegó a shodan [cinturón negro primer Dan] en tres meses. En lo que todo el mundo era deficiente era en las técnicas de muñeca, y él fue la persona que me las enseñó. Cuando entrené con él durante dos años me enseñó muchas cosas sobre cómo usar las muñecas. Nadie más me lo había enseñado. El res-
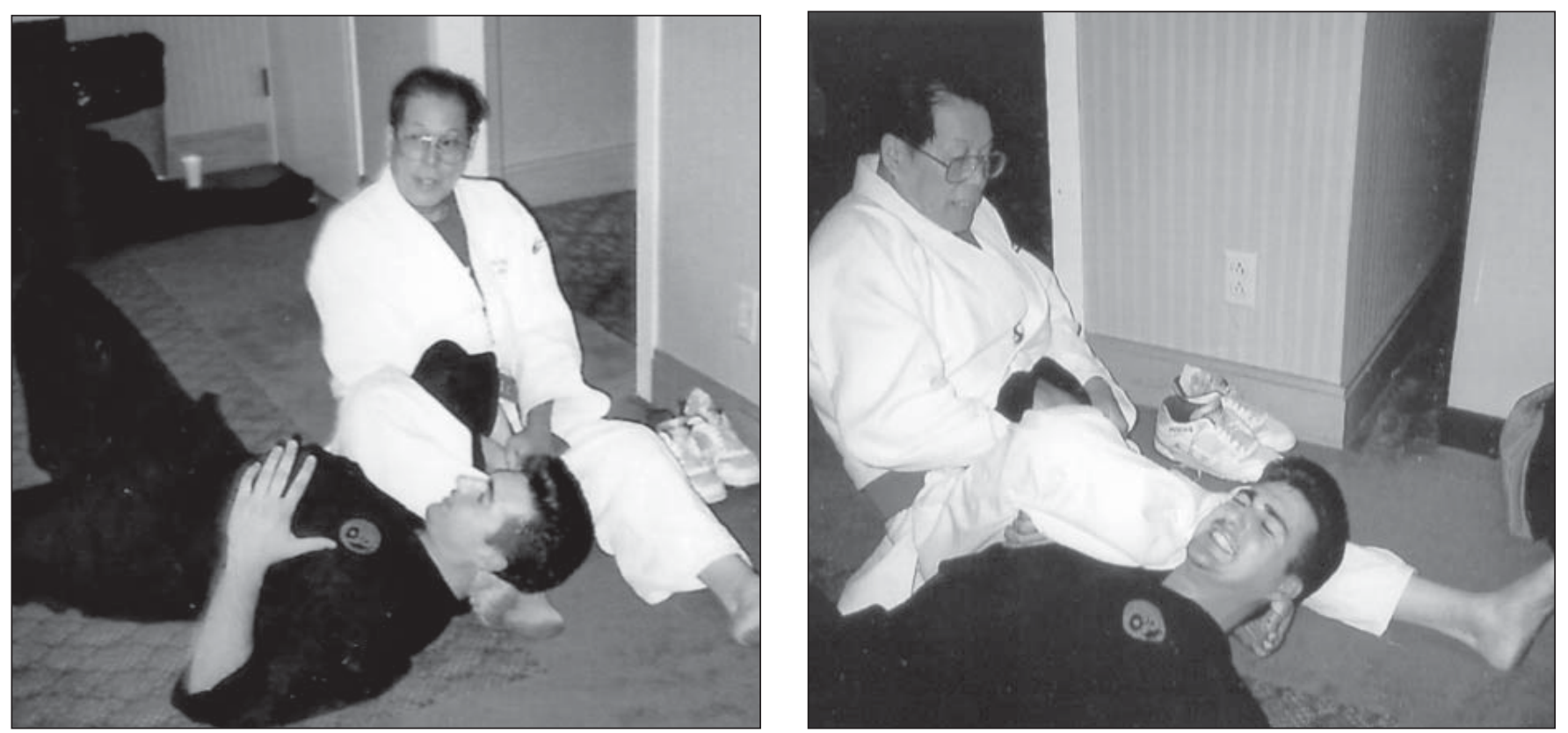
to de la gente simplemente usaba fuerza, pero estos suaves movimientos de la muñeca, empujar y tirar...

\section{Sobre su propio estilo -el Pequeño Círculo-:}

Me baso en diez principios:

1) El equilibrio es el número uno. Desequilibra a tu oponente mientras tú mantienes tu propio equilibrio. Entonces él necesitará utilizar su fuerza para recuperar su equilibrio. Has de tenerle desequilibrado, esto es muy importante.

2) Hay un momento para la estabilidad y otro para la movilidad. Cuando tienes movilidad, te mueves sobre la bola del pie. Cuando pivotas, la rodilla debe estar por encima o más allá de la punta del pie, no directamente sobre los talones. Para estabilizarte bajas tu cuerpo ligeramente, esto es esencial para los puñetazos y las proyecciones.

3) Colisión frontal de fuerzas. Si una persona te empuja, evítalo de un modo sencillo girando tu cuerpo levemente. No asumas el choque de la fuerza. Desvía, combina, redirige...

4) Resistencia mental. Puedes practicarla con un agarre a la muñeca con el codo doblado. Una persona te aplica el bloqueo, tú te concentras -el movimiento va más allá de la posibilidad de rotación de la muñeca- para soportar el dolor. En el momento en que la persona aprieta con su mano sobre tu muñeca, pierdes concentración.

5) Trata de precisar el dolor en el punto más pequeño posible, ya que transmisión de la energía a una zona amplia quiere decir que la energía se distribuirá ampliamente y se dirigirá menos energía hacia el punto donde se debería localizar el dolor.

6) Transferencia de energía. Con un ejemplo. En el brazo está lo que llamamos el tendón del tríceps. La primera cosa que hago cuando lo aplico en el codo, primero cojo la zona superior del brazo con mi palma y luego ataco esa parte. Transfiero mi energía desde la muñeca a través de mis dedos. Eso funciona bien.

7) Crea una base de trabajo. Siempre que haya mucho juego, tienes que crear una base. Puedes situarla en tu cuerpo o en cualquier sitio, en una pierna, no importa, cuando creas una base de trabajo quitas mucho juego al oponente.

8) Control en adherencia. La sensibilidad es muy importante. Te adhieres al oponente y evitas cada uno de sus intentos de escape. Debes mantenerte en contacto constante con tu oponente... Esto requiere sensibilidad.

9) Momento de rotación. Todo es como la imagen de un ocho tumbado.

10) Flujo de transición. Tienes que fluir de una técnica a otra, de una técnica a la siguiente.

\section{Compartiendo sus clases y técnicas con otros grandes maestros:}

Kohua [en hawaiano] significa "compartir, ayudar a otros", y ohana es "familia". Estas son cosas importantes en el viaje de las artes marciales, especialmente en el sistema del profesor Okazaki. Fue el tipo que enseñó todas estas cosas. Me las enseñó tardíamente, cuando llegué a ser cinturón negro. Tenía un salón de masaje de recuperación en la parte delantera, y en la parte trasera estaba el dojo. Allí era donde entrenábamos. Íbamos al salón de masaje antes y después de la clase, era una atmósfera en la que se nos cuidaba mucho. 

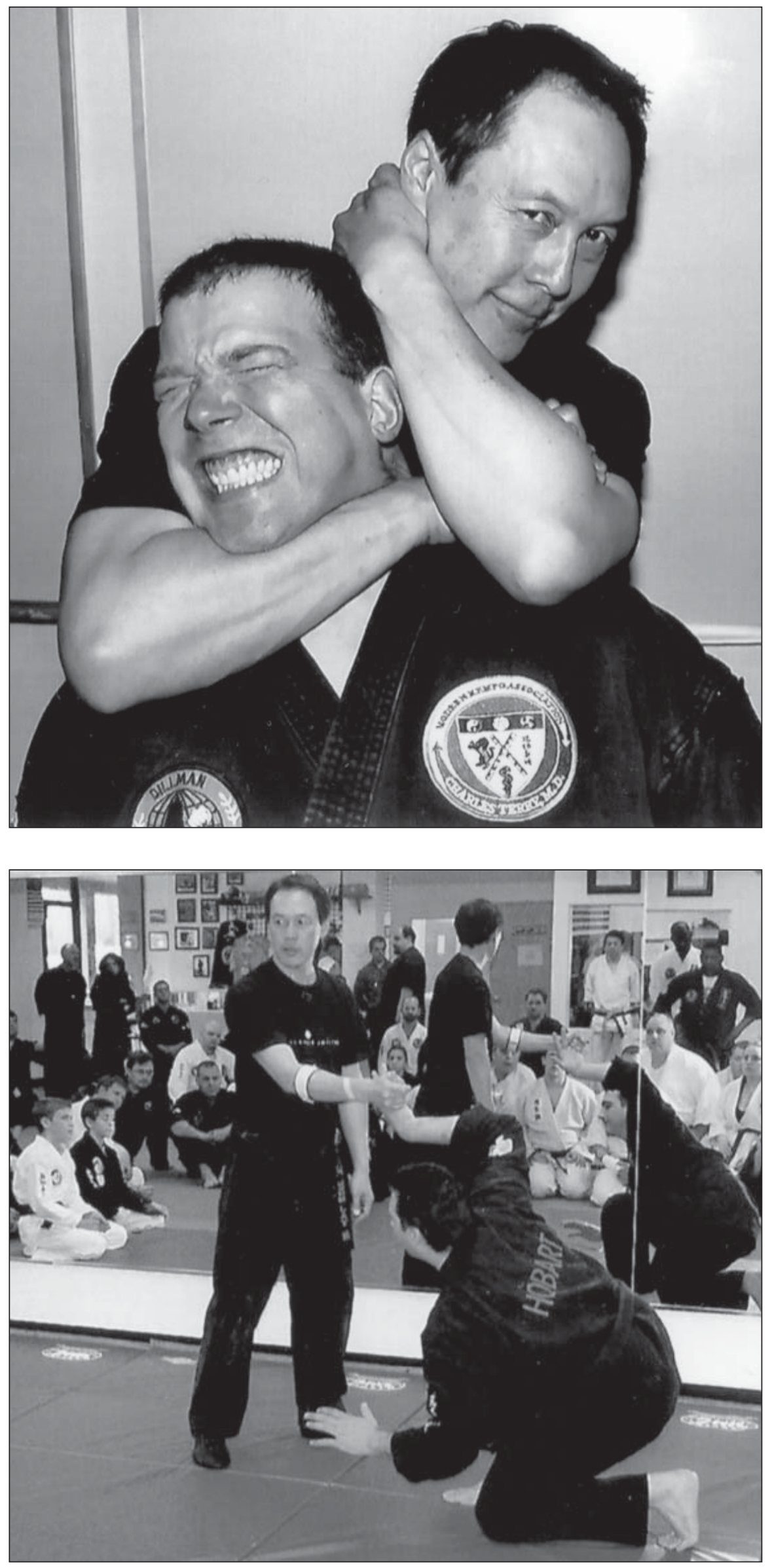

Leon Jay estrangulando a Rob Guihan.
Leon Jay aplica un bloqueo de dedo al autor. 
Aplicación de una técnica de resucitación (katsu) a un estudiante durante un seminario de Leon Jay.

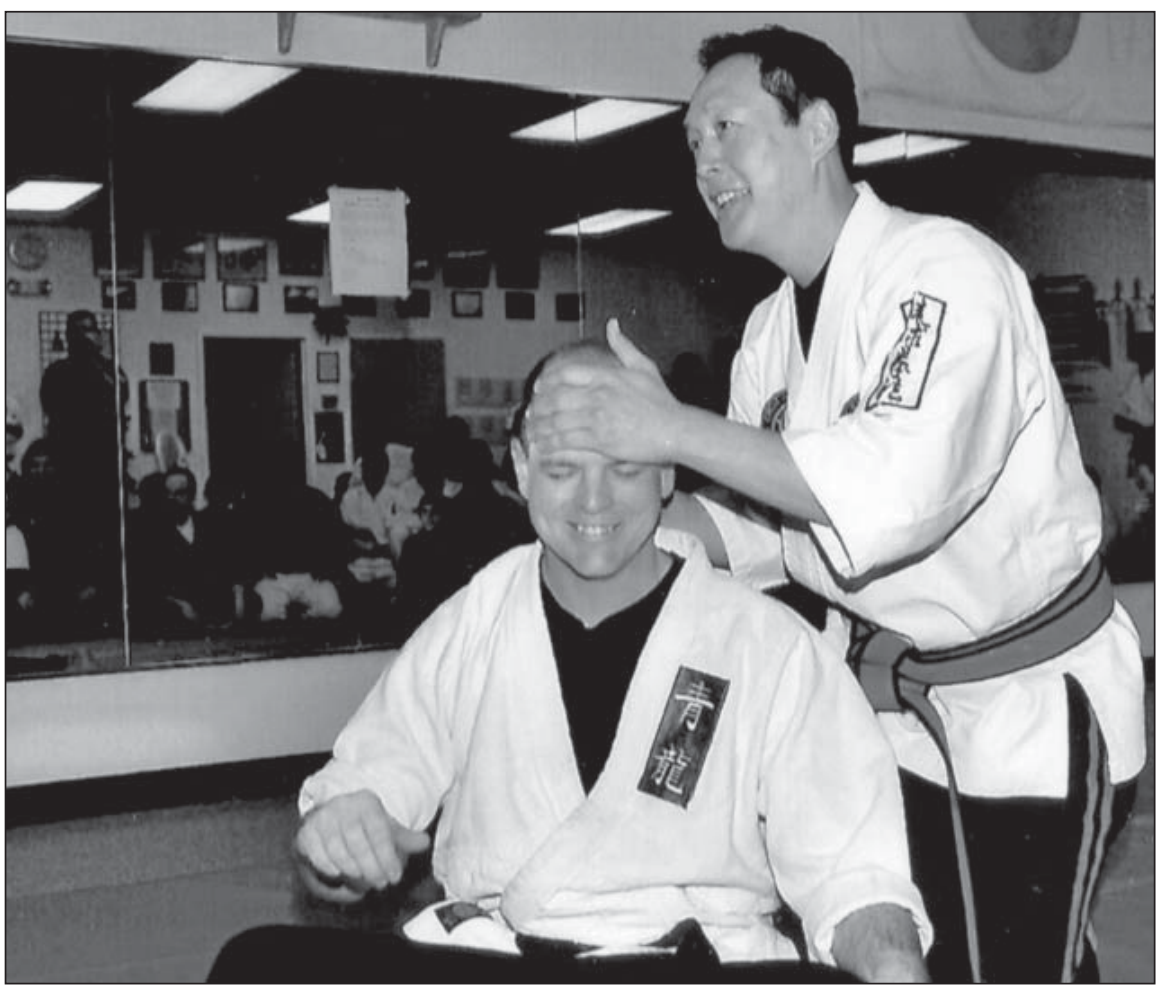

Nosotros [Remy Presas, George Dillman y Wally Jay] sentíamos que podíamos aprender algo unos de otros, y esto fue justamente lo que pasó.

Cuando Remy estaba enseñando, a veces yo podía meter baza, aunque no conociese su arte. Cuando enseñaba un movimiento a una persona, Remy decía: "Conoces, conoces las artes". Es el principio lo que es importante. Nos llevábamos realmente bien. Nunca estábamos celosos uno del otro. Enseñamos juntos en muchos países -Europa, Australia, Nueva Zelanda-, en todas partes. Oh, nos llevábamos bien.

\section{Sobre la importancia de aprender las artes de curación:}

Crear el máximo dolor sin dislocar la articulación: si no, es demasiado tarde, has hecho daño a la persona. Esto es tanto legal como ético. Aprendí masaje con el profesor Okazaki, primero con mi profesor, el sensei Juan Gómez. En cada sesión de trabajo pasábamos los últimos quince minutos a media hora dando un masaje al estilo Okazaki. Muchas veces, debido a las caídas, hay muchos achaques y dolores. Aquí es donde entra el masaje... Mi mujer, una sandan, ya no entrena mucho, pero todavía practica el masaje, un masaje realmente bueno. Es una señora realmente especial, una sanadora.

También el kuatsu [cómo revivir] es muy importante. Tenía un estudiante que era cinturón blanco. Estaba aprendiendo jujutsu en otra escuela. En aquella escuela alguien estranguló a otra persona y nadie sabía cómo revivirla, así que lo hizo él y luego me lo contó. Y dijo: "Sé cómo revivir, he leído su libro, Small Circle Jujitsu...”.

\section{Sobre sus relaciones con Bruce Lee:}

Me enseñó muchas cosas y le enseñé muchas cosas. Se llevó una buena patada de mi juego de piernas. Yo era muy ligero. Me movía a su alrededor depri- 


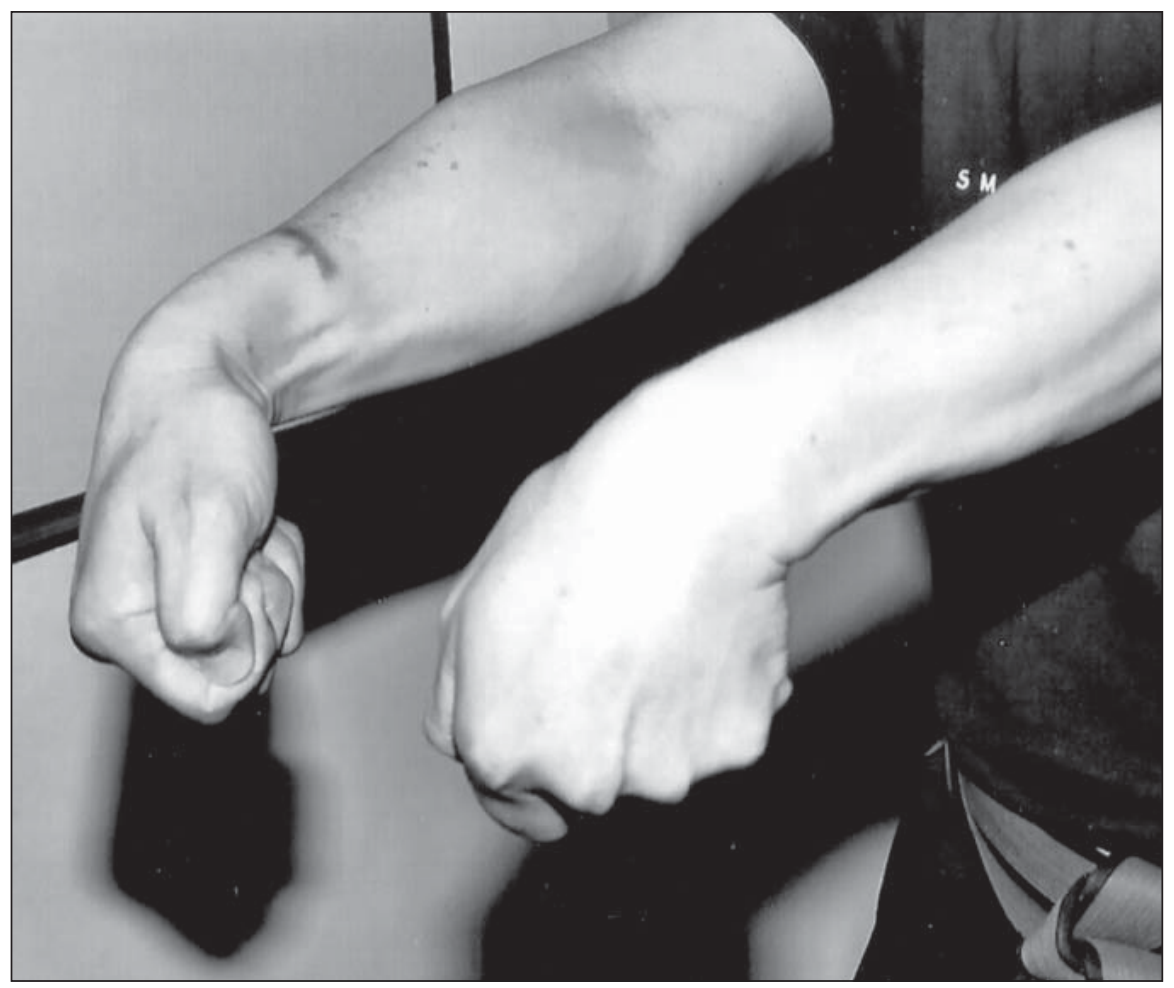

sa, muy ligero. Practicaba su estilo de mover los pies y yo practicaba el mío. Disfrutábamos de las habilidades del otro. Bruce era algo especial. Nunca he visto un tipo como aquel, tan rápido y que pudiese pegar tan duro. Medía como $1,67-1,70 \mathrm{~m}$. y pesaba como $61 \mathrm{~kg}$, y oye, cómo golpeaba y cómo se movía de rápido. Nos llevábamos realmente bien... Le enseñé algunas de las técnicas de mano que hacía. Posteriormente uno de mis amigos que aprendió Wing Chun usó el Pequeño Círculo. Todas las veces que alguien sacaba su mano, aplicaba un bloqueo del Pequeño Círculo. Decía que Bruce podía ver lo que podría pasar si una persona se movía hacia una determinada posición, le aplicaría una sujeción; si se movía hacia otra, le aplicaría otra técnica. No sabía que el Pequeño Círculo se acomodaría tan bien al gongfu, pero supongo que Bruce lo vio... De él aprendí la fuerza y la velocidad de los golpes de puño. Sencillamente se aceleraba, muy rápido. Siempre se estaba moviendo.

\section{Sobre lo que hace a una persona un maestro:}

Un maestro de las artes marciales tiene que tener un grado suficientemente alto y estar realmente formado. Hay algunos que piensan que ya lo tienen dominado simplemente porque tienen el cinturón negro. Se unen a diferentes organizaciones: para obtener el cinturón negro primer Dan aquí, y después se apuntan a otra y obtienen el segundo Dan, después se marchan y se apuntan a otra y obtienen el tercer Dan. ¡Antes de que te enteres son décimo Dan! Hay muchas personas de este tipo hoy en día. Hay muchas, en los Estados Unidos y en cualquier parte.

Investigo mucho las técnicas... ¡A Aprendo mucho cuando intento dormir! Siempre cambiando, porque es necesario. Siempre estoy buscando un mejor modo de hacer las cosas. No puedes luchar en la Segunda Guerra Mundial con armas de la Primera Guerra Mundial, y si lo haces no eres un maestro.

El profesor Don Jacob es mi mejor amigo. Es de Trinidad y es fabuloso. Hace cualquier cosa y es bueno en ello. Tiene como 49 años y lo conocí
León Jay demostrando el principio de de la acción en dos direcciones. 
Leon Jay demostrando un bloqueo de muñeca (1), una palanca de brazo (2) y un bloqueo de codo (3).
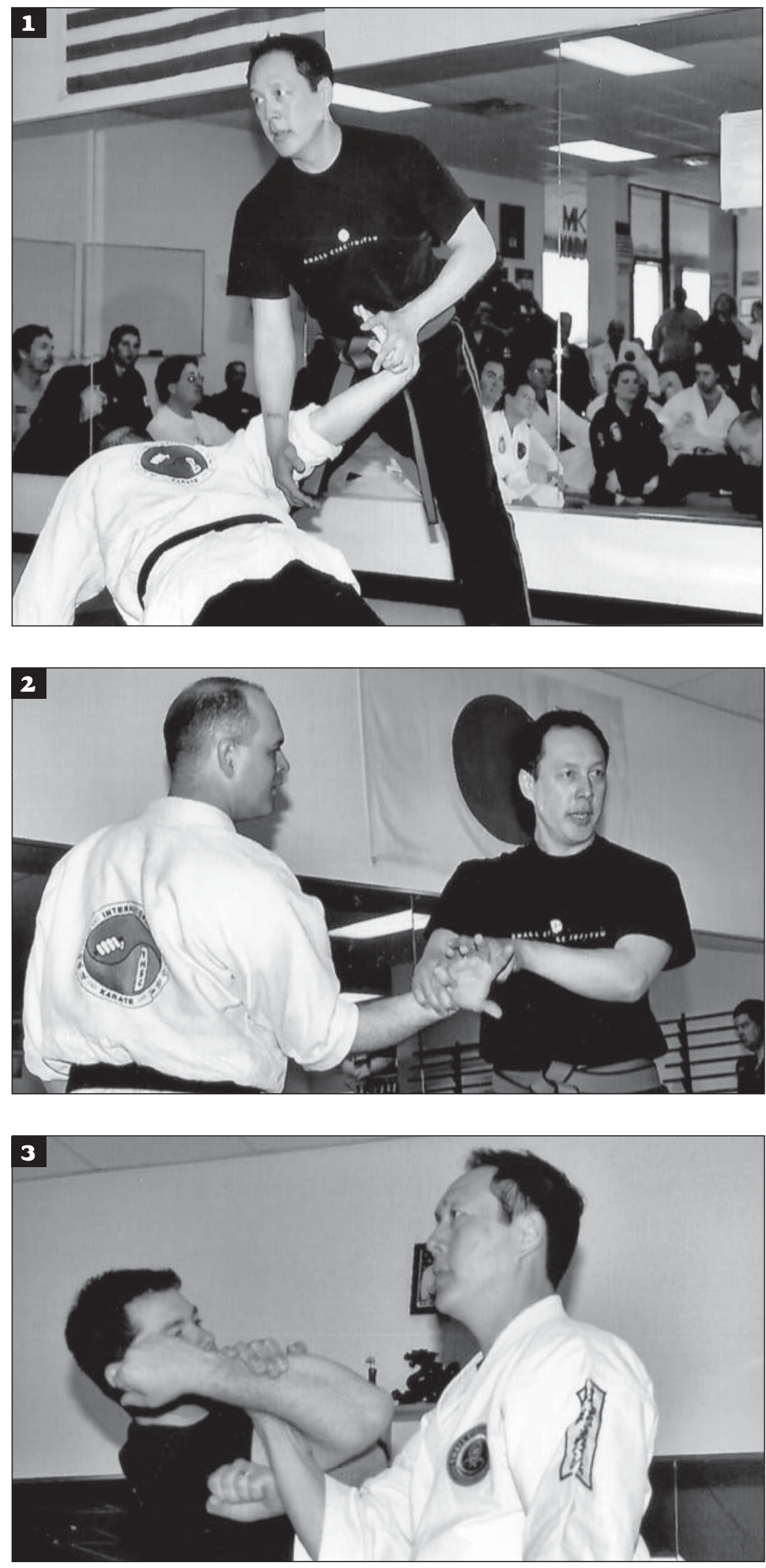
cuando tenía 26, en Toronto, y llegamos a ser buenos amigos. Enseña su propio estilo, el Purple Dragon Jujutsu [Jujutsu del Dragón Morado]. Es realmente un maestro, el mejor amigo que nunca he tenido en mi vida.

También pienso que el sentido del humor es muy importante. Hace que una persona se relaje. Siempre tengo algunos chistes sobre mis técnicas. Las personas a las que enseñas a veces tienen miedo, porque eres muy conocido, pero después descubren que eres como cualquier otro. Tú tienes sentido del humor, creo que eso es importante.

\section{Sobre cómo las artes marciales han evolucionado para reflejar los peligros emergentes en la sociedad:}

Me aseguraría de hacer daño a un atacante. No puedes hacerle sólo un poco de daño y permitir que se vaya. Tienes que hacer que realmente se acuerde de ello. Creo que las cosas han cambiado. El año pasado en Oakland tuvimos 104 homicidios y Oakland no es grande... para hacer que la gente comprenda tienes que hacerles daño, si no se vengarán.

\section{Sobre la enseñanza y el entrenamiento:}

Sinceramente, no soy un buen competidor. Nunca me he inscrito en un torneo en toda mi vida. Me acuerdo cuando me uní al grupo del Kodokan en California. El primer día participamos en nuestro primer torneo. Aquellos cinturones negros simplemente se rieron de nosotros. El tipo que tenía el grado más alto hizo algún tipo de comentario y todo el mundo se rió. Yo estaba sentado con todos los instructores y se giraron para mirarme, estaba dolido. Abandoné el lugar y dije que no volvería hasta un año después, y lo hice. Mi sobrino, Bill Sniffen, estaba allí. En su primer torneo, el tipo agarró su gi [uniforme], y casi estaba acabado. ¡Un año después lanzó a cinco tipos en hilera! Mi familia solía vencer, mis hijos, mis sobrinos, y posteriormente mis estudiantes empezaron a ganar. Fue un gran éxito para mí. Ganamos en México, Hawai, Canadá... Tuvimos muchos campeones nacionales en judo.

\section{Sobre su legado:}

Quiero que otros enseñen del modo en que yo lo he hecho, enseñar agradablemente. Nunca he gritado a un estudiante por que perdiese un enfrentamiento. Recuerdo un entrenador que entró corriendo en el tapiz -sus chicos estaban siendo vencidos de muy mala manera- y gritó: “iTe dije que tirases!”. Eso no es correcto, es la cosa peor que puedes hacer. Es importante pensar también en los estudiantes. Veo a esas personas enfadarse con sus estudiantes porque no hacen lo que ellos quieren. No pueden hacerlo. No todo el mundo es igual, ya sabes. Sé muy compasivo con los estudiantes y con los que aprenden despacio... Creo que deberías enseñar con amor, no con intención de hacer daño a nadie. Con el Pequeño Círculo puedes controlar la cantidad y grado de dolor. 